\title{
ESTABLISHMENT OF THE NETWORK AND THE SURVEILLANCE FOR WILDLIFE HEALTH IN ALBANIA
}

\author{
K. $\mathrm{KORRO}^{1,2} \&$ L. CARA ${ }^{3}$ \\ ${ }^{1}$ Faculty of Veterinary Medicine, Agricultural University of Tirana, Albania; \\ ${ }^{2}$ Albanian Focal Point for Wildlife for World Organization for Animal Health \\ (OIE) ${ }^{3}$ Food Safety Institute, Animal Health Department, Rabies Laboratory
}

\section{Summary}

Korro, K. \& L. Cara, 2021. Establishment of the network and the surveillance for wildlife health in Albania. Bulg. J. Vet. Med., 24, No 3, 450-457.

Wildlife health surveillance is important in conservation of the wild species but also to identify the wild animal reservoirs of pathogens affecting human and domestic animals. The Wildlife Health Surveillance plays an important role in ensuring veterinary public health and human health and contributes to safe animal-human-ecosystems interfaces. The Albanian network for wildlife health surveillance was established in 2009. The building of a surveillance network and system for wildlife health began with the support of World Organization for Animal Health (OIE), Technical Assistance and Information Exchange instrument of the European Commission (EU TAIEX Programme, Ministry of Education of Albania and World Bank. Training and staff preparation for wildlife health surveillance was provided. In addition, a research laboratory for surveillance of some important wildlife disease was built. The surveillance for rabies in wild carnivores, HPAI in wild birds, the hantaviruses in rodents and tularaemia in wild rabbits, which are also zoonoses, are some results of these endeavours in Albania. Albanian public veterinary health and public human health envisage improving the strategy for wildlife health surveillance under One Health approach in order to ensure veterinary health, public health and environmental health and to contribute to the OIE wildlife health information system as well.

Key words: disease surveillance, wildlife health surveillance network

Wildlife health surveillance is important in conservation of the wild species but also to identify the wild animal reservoirs of pathogens affecting human and domestic animals. The wildlife health surveillance plays an important role in ensuring veterinary public health and human health and contributes to safe animal-human- ecosystems interfaces. Wild animal populations movement does not respect national borders and as a result, a wildlife disease event occurring in one country may provide advance warning to neighbouring countries of a possible future disease event in their territories (Kuiken et al., 2011). 
The World Organization for Animal Health (OIE) established a permanent Working Group on Wildlife Diseases in 1993. The Working Group comprises six of the world's leading scientific experts in their subject areas coming from all regions of the world. It collects, analyses and disseminates information on almost 40 diseases affecting wildlife, either in the wild or in captivity. The Working Group has prepared OIE recommendations and overseen numerous scientific publications on the surveillance and control of the most important wildlife diseases (Vallat, 2008).

In Europe, a formal interest to strengthen the wildlife diseases surveillance exists since 1995 by assessing the nature of wild animal disease surveillance in Europe and making a catalogue of the organisations and individuals responsible for such surveillance (Leighton, 1995). In February 2010 after the agreement on 15 October 2009 at the Brussels meeting with professionals mainly by the European Wildlife Disease Association (EWDA), the European Network for Wildlife Health Surveillance was established. The goals of this network are to improve procedures for the rapid exchange of information, harmonise procedures for investigation and diagnosis of wildlife diseases, share relevant expertise, and provide training opportunities for wildlife health surveillance (Kuiken et al., 2011).

Albania is situated in the Balkan region of Europe bordering Montenegro to the north-west, Kosovo to the north-east, Republic of North Macedonia to the east and Greece to the south. The wildlife health surveillance of Balkan region is of great national, regional and international importance. Albania and every other Balkan country are obliged to build national and regional wildlife health surveillance systems and also its network regarding the diseases and concerns of wildlife health. The wildlife health surveillance is actually mandatory for the authorities of Albania and also the Balkan States as required by OIE, EU, Food and Agriculture Organization (FAO), World Health Organization (WHO) and other organizations where the countries participate.

The paper presents the endeavours to establish Albanian Network for the Wildlife Health Surveillance and provide some orientation for the improvement of wildlife health surveillance and wildlife diseases control in Albania.

\section{ESTABLISHMENT OF THE WILDLIFE HEALTH SURVEILLANCE NETWORK IN ALBANIA}

Since its establishment in 1929 by Bilal Golemi, a honorable patriot, the Veterinary Service in Albania was interested and developed the surveillance and control of the animal diseases in the country. During the centralised state economy, the veterinary service continued to develop the surveillance and control of animal diseases, including wildlife. In 1990 after the fail of the state regime, the Veterinary Service had difficulties in delivering the veterinary services.

The establishment of the Wildlife Health Surveillance Network in Albania started in 2008. The Ministry of Agriculture of Albania and OIE nominated a focal point for wildlife in Albania. The Albanian focal point for wildlife created the national work group for the establishment of a national surveillance network related to wildlife. The members of Network of Wildlife Health Surveillance of Albania are state veterinarians, biologists and statisticians. An important role plays the veterinarian district focal points at the Regional Directorates of State Veterinary 
Service which meet every three months to discuss different issues on wildlife health. The national work group was trained by OIE and the European Commission through the programme of the Technical Assistance and Information Exchange instrument of the European Commission (TAIEX). During 2009-2012, two training workshops were organised by TAIEX programme engaging the best European experts in the wildlife surveillance field. From 2014 to 2017, a research scientific laboratory for the wildlife disease surveillance was build in the Faculty of Veterinary Medicine in Albania with the support of UNILAB project; a cooperation of the World Bank and the Ministry of Education of Albania. The European "Wildtech Project" under the Seventh Framework Program (FP7) supported additional qualification of the working group of the network for wildlife disease surveillance not only of Albania but also of Kosovo, Montenegro and some other parts of Republic of North Macedonia. In addition, a cooperation of the work group of the Wildlife Health Surveillance Network with the Food Safety and Veterinary Institute (FSVI) in Tirana has shown its first success by building a map of several important diseases spread in Albania.

The Wildlife Health Surveillance Network of Albania has cooperated with other networks of the Western Balkan countries on wildlife health issues. During 9-10 May 2013, the first National Balkan Conference for Wildlife Diseases was organised in Tirana and presented the results of the surveillance of wildlife diseases. This conference was important also in establishing a regional network for the Western Balkan. The members of this network are Albania, Republic of North Macedonia, Kosovo and Montenegro. The conference supported also the coordina- tion of common studies of wild animals.

Another contribution in the Wildlife Health Surveillance in Albania is the cooperation with FSVI in Tirana and the Protection Against Zoonotic Diseases, Albania (PAZA) project funded by the European Union during 2013 to 2018 , which contributed in some activities on the surveillance and control of zoonotic diseases that affect wild fauna. The vaccination against rabies of wild carnivores in Albania was conducted from 2014 to 2019 by the PAZA EU project based on the surveillance information of the Wildlife Health Surveillance Network of Albania.

The establishment of the network of Wildlife Health Surveillance has supported different activities for wildlife health surveillance in Albania. The surveillance for rabies in wild carnivores, HPAI in wild birds, the hantaviruses in rodents and tularaemia in wild rabbits, which are also zoonoses, are some results of these endeavours in Albania. These results, presented in following parts of the article, are important not only for veterinary public health, public health and environmental health but also for the scientific community in the country and the Balkan region and OIE wildlife health information system.

\section{SURVEILLANCE OF WILDLIFE DISEASES}

\section{HPAI surveillance in wild birds}

Albania first reported $\mathrm{H} 5 \mathrm{~N} 1$ in poultry (chickens) on 7 March 2006 in Çukë, Saranda (Korro, 2007; Korro et al., 2007; Anonymous, 2014). Following this event, 2,413 dead wild birds were gathered by Wildlife Health Surveillance network during 2007-2013 and analysed for HPAI in the FSVI. The laboratory diagnosis for the 
presence of H5 was confirmed by haemoagglutination (HA) and haemoagglutination inhibition (HAI) tests. Standard reagents, antigen $\mathrm{H} 5, \mathrm{H} 7, \mathrm{H} 9$, and standard positive serum were imported from GD, Animal Health, The Netherlands. Furthermore, ELISA and HAI were used on serum samples. The isolation of the virus was done in Madin-Darby canine kidney (MDCK) tissue cultures. The final confirmation by PCR for the presence of H5N1 was carried out by the Reference Laboratory in Weybridge, UK. Seven out of 2,413 wild birds resulted positive (Table 1). There were three positive samples from eagles and four from wild ducks.

\section{Rabies surveillance}

From 2002 to 2007, the wild carnivores were caught by Wildlife Health Surveillance network and tested for the presence of rabies virus (Korro, 2007; Korro et al., 2008; 2009a). All samples (brain from suspected animals) were diagnosed with FAT, and MIT at the Rabies Laboratory to FSVI: the only lab in the country that is capable of diagnosing rabies. The reporting system is based on an alert notification from practitioner veterinarians and regional veterinary authorities. FAT, which is also a confirmatory test for detection of antigen and virus inclusion in brain tissues of wild carnivores (Table 2), was performed directly in smears prepared from hippocampus region (Ammon's horn), cerebellum and medulla oblongata. Smears were fixed in high-grade cold acetone. Brain smears were stained with fluorescent anti-rabies monoclonal antibody (MAB) conjugate and results of test, the specific intracellular viral inclusions were identified by microscopic examination with UV light. The FAT gives reliable results on fresh specimens within a few hours in $90-99 \%$ of cases. The sensitivity of FAT depends on the specimen, on the type of infecting rabies virus and on the proficiency of the diagnostic laboratory. Positive results in FAT were confirmed with MIT. Brain tissue from positive sam-

Table 1. Surveillance of H5N1 in wild birds during 2007-2013.

\begin{tabular}{lc}
\hline Bird species & $\begin{array}{c}\text { Total number of samples (num- } \\
\text { ber of positive samples) }\end{array}$ \\
\hline Common quail (Coturnix cortunix) & $50(0)$ \\
Doves (Columbia livia) & $200(0)$ \\
Teal (Anas crecca) & $70(0)$ \\
Marsh harrier (Circus areuginosus), & $53(3)$ \\
Common buzzard (Buteo buteo) & \\
Geese (Anser anser) & $210(0)$ \\
Gulls (Egretta alba) & $60(0)$ \\
Moorhen (Gallinula chloropus) & $165(0)$ \\
Snipe (Gallinago gallinago) & $125(0)$ \\
Pelicans (Pelecanus crispus); & $340(0)$ \\
Great white egret (Egretta alba) & \\
Various kinds of birds & $350(0)$ \\
Black throated loon (Gavia artica), & $200(4)$ \\
Little grebe (Tachybaptus ruficollis) & \\
\hline
\end{tabular}


Table 2. Results of the surveillance in rabies in wild carnivores during 2002 to 2007 (Korro et al., 2008).

\begin{tabular}{lrrrrrr}
\hline & \multicolumn{6}{c}{ Total number of samples (Number of positive samples) } \\
\hline Carnivores species /years & \multicolumn{1}{c}{2002} & \multicolumn{1}{c}{2003} & 2004 & 2005 & 2006 & \multicolumn{1}{c}{2007} \\
\hline Fox (Vulpes vulpes) & $26(1)$ & $33(2)$ & $17(0)$ & $23(0)$ & $21(1)$ & $22(0)$ \\
Weasels (Mustela nivalis) & $2(0)$ & $5(0)$ & $7(0)$ & $4(0)$ & $2(0)$ & $4(0)$ \\
Wildcats (Felis silvestris) & $2(0)$ & $1(0)$ & $2(0)$ & $0(0)$ & $1(0)$ & $0(0)$ \\
Wolf(Canis lupus) & $15(0)$ & $12(0)$ & $11(2)$ & $14(0)$ & $12(0)$ & $3(0)$ \\
\hline Total & $45(1)$ & $51(2)$ & $37(2)$ & $41(0)$ & $35(1)$ & $27(0)$ \\
\hline
\end{tabular}

ples were inoculated intracerebrally into 9-12 g adult albino mice, and 4-28 days post inoculation, mice were examined for the presence of rabies virus inclusions in brain using FAT. The summary results of the surveillance in wild carnivores are presented in Table 2 (Korro et al., 2008).

From 2006 (Korro et al., 2009b) to 2010, another laboratory diagnostics was carried out by the FSVI in 409 collected live bats under the framework of the national Wildlife Health Surveillance. The bats were taken from the northern, central and southern part of Albania. All 409 bats were sampled with the above diagnostic test and procedure and resulted negative for rabies. From the identification and monitoring of the bats for rabies, it was noticed that Eptesicus serotinus, which is thought to be one of the main vectors of the transmission of rabies, is still not identified in Albania.

\section{Hantavirus surveillance}

From July to November 2006 the Albanian public health authorities conducted a study to detect the hantavirus infection. Ninety-five small mammals were trapped in different sites of Albania in 22 districts (Papa et al., 2007). Total ribonucleic acid (RNA) was extracted from homogenised rodents' tissues and reverse transcriptase- nested polymerase chain reaction (RTnested PCR) for amplification of a 600-bp region of $\mathrm{S}$ segment was performed to check for probable hantavirus infection. PCR products were sequenced and phylogenetic analysis using PHYLIP was performed. The yellow-necked mouse (Apodemus flavicollis) was the predominant rodent species $(63.15 \%)$. No striped field mice (A. agrarius) or red bank voles (M. glareolus) were captured and $6.3 \%$ of small mammals (10\% of A. flavicollis) were positive for Dobrava-Belgrade (DOB) virus. Positive A. flavicollis were detected in 4 districts (Papa et al., 2007).

A first insight into the epidemiology of hantaviruses in Albania was studied also from the Albanian public health authorities in 263 small mammals (248 rodents, 15 insectivores) captured in 352 locations in 29 districts and tested for hantavirus infection from 2006 to 2007 (Papa et al., 2011). Dobrava-Belgrade virus (DOBV) was detected in 10 of 148 (6.7\%) Apodemus flavicollis rodents. DOBV-positive $A$. flavicollis were detected in six districts (Diber, Korce, Kolonje, Librazhd, Pogradec, and Vlore). The obtained nucleotide sequences were highly similar to each other and to DOBV sequences from northwestern Greece (Papa et al., 2016). 


\section{Tularaemia surveillance}

During 2014 to 2015 and spring of 2016, the Wildlife Health Surveillance network conducted a study to detect tularaemia. The samples were taken from European brown hares in different villages of $\mathrm{Re}$ public of North Macedonia, such as: Debresh, Nerove, Allbance, Presille, Bellushine, Haracine, Tearce as well as villages of Pogradec district in Albania near the border of Republic of North Macedonia (Korro et al., 2018). The laboratory diagnostics of Francisella tularensis infection was conducted at the Faculty of Veterinary Medicine of Tirana, Albania. Forty-two out of 180 samples were positive from slide agglutination test using stained bacteria (Bioveta Inc.). Two out of fourteen positive samples had gross pathological lesions in the organs such as, lungs, pericardia, kidneys and bone marrow. Granulomatous inflammation was considered as an indicator of Francisella tularensis infection. Foci of granulomatous inflammation with central necrosis were found in the liver, bone marrow, mammary gland, spleen and mediastinal lymph nodes (Korro et al., 2018).

The Albanian Wildlife Health Surveillance Network has been important to contribute in the activities for the identification of the wildlife diseases in Albania and can play a role in addressing the early warning, surveillance, response and control. The early warning, surveillance, response and control of wildlife disease need to be outlined by regulatory framework and integrated with the one of the livestock and human health (given the fact that the reported wildlife diseases are zoonoses). The wildlife disease control requires a combination of the disruption of cycle of infection in wildlife, livestock and humans. Therefore, the cooperation between the Wildlife Health Surveillance
Network with veterinarian service surveillance network, public health service network and eviromental health professionals are indispensable for the control of these diseases. The Albanian Wildlife Health Surveillance Network should improve its communication and increase awareness of its member on existing and new disease risk which might appear within the country, in the region and the European countries.

The surveillance studies carried out in Albania during the last decade clearly demonstrate the potential risk and infection of HPAI, rabies, hantaviruses and tularaemia. Wildlife diseases identified from the surveillance in Albania represent a real threat to human, wildlife and domestic animal health.

The surveillance methods are purposive and identify the risk for domestic animals and human health in Albania. Passive surveillance needs to be appropriately strengthened in order to ensure the detection of a pathogen as soon as it is introduced. Passive surveillance of both wildlife and livestock diseases needs to be strengthened as active surveillance cannot guarantee the detection of any pathogens.

An early detection needs to be addressed by considering the epidemiology of the pathogen and the wildlife host populations. Active surveillance will play a pivotal role during outbreak management, especially of the highly transboundary diseases such as HPAI. The risk-based active surveillance is needed in order to identify the magnitude of the wildlife disease situation and other disease threats that might be present in the Albania. The risk areas need to be identified. Risk assessment procedure has to identify infection and its risk for rare and endangered species living in the complex ecosystems. Methodologies for appropriate disease 
risk mitigation in wildlife and wildlifehuman-livestock interface have still to be developed in the country. Evaluation of zoonotic diseases of wildlife as a threat to human health must be considered not only at national level but also at regional and European level.

\section{CONCLUSIONS}

The building of surveillance structures of wildlife health in Albania attempts to fulfill the obligation of OIE, European Union and respective international organisations. It also assists veterinary and human health authorities in accordance with the 'One Health' approach.

The first attempt on surveillance and monitoring of wildlife diseases in Albania requires further serious evaluation and support not only from the government but also from foreign donors in order to strengthen the sector of surveillance and monitoring of wildlife diseases.

The improvement of the laboratory for the monitoring of wildlife diseases at the Faculty of Veterinary Medicine of Albania is highly important to perform and support various important studies and investigation for wildlife health. This laboratory needs additional technical and technology resources which will make possible the support of the surveillance and control of wildlife diseases, which some of them are zoonoses, in Albania and in Balkan region especially those spread through country borders.

\section{REFERENCES}

Anonymous, 2014. FAO OIE WHO (17 March 2014) H5N1 highly pathogenic avian influenza: Timeline of major events, https://www.who.int/influenza/human_ani mal_interface/H5N1_avian_influenza_upd ate20140317.pdf (Date last accessed 11 February, 2019).

Korro, K., 2007. First monitoring about wildlife diseases in Albania. In: Proceedings of the EWDA Conference, www.svepm.org. uk/f-Download-d-file.html?id=1405 (Date last accessed 07 November, 2019).

Korro, K., F. Selami, A. Shumeli, K. Berxholi, L. Qafmolla \& L. Cara, 2007. Study of Avian Influenza in the Wildlife Habitat of Albania, In: Proceedings of the Ecology and Management of Wildlife Diseases, Conference $12^{\text {th }}-16^{\text {th }}$ November 2007 , Central Science Laboratory York, UK. https://www.researchgate.net/publication/2 87202425 Study of Avian Influence in the_Wildlife_Habitat_of_Albania (Date last accessed 07 November, 2019).

Korro, K., K. Berxholi, L. Klimi, R. Keci, K. Qafmolla \& B. Bizhga, 2008. Study of rabies in the wild carnivores of Albania. Newsletter of the Wildlife Disease Association, pp. 14-16, https://www.wildlifedisease.org/wda/Portals/0/WDANewsletterJuly2008.pdf (Date last accessed 07 November, 2019).

Korro, K., K. Berxholi, K. Lefter, R. Keci, L. Qafmolla \& B. Bejo, 2009a. Targeted rabies surveillance in wild carnivores in Albania. Rabies Bulletin Europe, 33, 7. https://www.researchgate.net/publication/2 22102005 Targeted_rabies_surveillance_ $\mathrm{i}$ n_wild_carnivores_in_Albania (Date last accessed 07 November, 2019).

Korro, K., K. Sulaj, L. Cara, L. Qafmolla \& S. Duro, 2009b. Monitoring of rabies in bats in Albania. In: Proceedings of the $3^{\text {rd }}$ Symposium of the Belgian Wildlife Disease Society, Wildlife Disease Surveillance, Brussels, 16 October 2009, p. 26. http://www.bwds.be/symposium/3\%20th\% 20symposium $\% 202009 /$ Abstractbook $\% 20$ BWDS\%20symposium\%202009\%20Wildl ife\%20Disease\%20Surveillance.pdf (Date last accessed 07 November, 2019).

Korro, K., M. Elezi \& B. Elezi, 2018. Monitoring of tularemia in brown hare population in the Southern Part of Albania and the Western Part of FYROM Macedonia. 
In: Proceedings of the $2^{\text {nd }}$ International Congress of Veterinary Microbiology, Antalya, Turkey 2018, https://www.researchgate.net/publication/328841775_M ONITORING_OF_TULAREMIA_IN_BR OWN HARE POPULATION IN THE SOUTHERN_PART_OF_ALBANIA_AN D THE WESTERN_PART OF FYROM MACEDONIA (Date last accessed 07 November, 2019).

Kuiken, T., M.-P. Ryser-Degiorgis, D. GavierWiden \& C. Gortazar, 2011. Establishing a European network for wildlife health surveillance. Revue scientifique et technique (Office International des Epizooties), 30 , 755-761.

Leighton, F. A., 1995. Surveillance of wild animal diseases in Europe. Revue scientifique et technique (Office International des Epizooties), 14, 819-830.

Papa, A., E. Rogozi, E. Velo, E. Papadimitriou, S. Bino \& A. Antoniadis, 2007. Genetic detection of hantaviruses in Albanian rodents. In: Proceedings of the VII International Conference on HFRS, HPS and Hantaviruses, Buenos Aires, Argentina, https://www.researchgate.net/publication/2 71480453_Genetic_Detection_of_Hantavi ruses in Albanian Rodents (Date last accessed $0 \overline{7}$ November, 2019).

Papa, A., E. Rogozi, E. Velo, E. Papadimitriou \& S. Bino, 2016. Genetic detection of hantaviruses in rodents, Albania. Journal of Medical Virology, 88, 1309-1313.

Vallat, B., 2008. Improving wildlife surveillance for its protection while protecting us from the diseases it transmits. World Organisation for Animal Health (OIE); http://www.oie.int/en/for-themedia/editorials/detail/article/improvingwildlife-surveillance-for-its-protectionwhile-protecting-us-from-the-diseases-ittransmit/ (Date last accessed 07 November, 2019).

Paper received 24.09.2019; accepted for publication 31.10.2019

\section{Correspondence:}

Kastriot Korro

Faculty of Veterinary Medicine,

Agricultural University of Tirana, Albania, e-mail: kkorro@ubt.edu.al 